\title{
A Study to Evaluate the Effectiveness of Self-Instructional Module on Knowledge Regarding Risk Factors and Prevention of Stomach Cancer among Professional Students at Selected Colleges, Bangalore
}

\author{
Khaling Rai Dipa ${ }^{* 1}$, KC Sudikshya ${ }^{2}$, Malla Chandani \\ ${ }^{* 1}$ Department of Medical Surgical Nursing, National Medical College Nursing Campus, Birgunj, Nepal \\ ${ }^{2}$ Department of Anatomy, National Medical College Birgunj, Nepal \\ ${ }^{3}$ Department of Paediatric Nursing, National Medical College Nursing Campus, Birgunj, Nepal
}

\section{ABSTRACT}

Background: Cancer is one of the most important causes of morbidity and the magnitude of the problem is gigantic. Gastric cancer is the second leading cause of cancer mortality in the world as well as in India. Majority of the patients are diagnosed at an advanced stage. It is widely held that $80 \%$ to $90 \%$ of stomach cancers may be attributable to environmental and life style factors such as tobacco, alcohol and dietary habits. Primary cancer prevention refers to avoiding cancer causing substances in the environment or dietary elements associated with increased risk.

Methods: The research approach adopted for the study was experimental approach and research design selected for the study was experimental one group pre-test post-test design. Simple random sampling technique was used for the selection of 60 professional students. The tool used for the data collection was structured knowledge questionnaire, which had two sections. Section-A provides about socio-demographic data and Section-B deals with knowledge on risk factors and prevention of stomach cancer. Collected data was analyzed by using descriptive and inferential statistics in terms of frequencies, percentage, mean, standard deviation, chi-square values and ' $t$ ' test.
Results: The result of this study showed that in pre-test $43(71.67 \%)$ of them had inadequate level of knowledge, $17(28.33 \%)$ of them had moderate level of knowledge and none of them had adequate level of knowledge regarding risk factors and prevention of stomach cancer whereas in post-test, $40(66.67 \%)$ of them had adequate level of knowledge, 20(33.33\%) of them had moderate level of knowledge and none of them had inadequate level of knowledge regarding risk factors and prevention of stomach cancer. The enhancements mean score was $16.72 \pm 1.28$.

Conclusion: The study was found to be effective in improving the knowledge of professional students regarding risk factors and prevention of stomach cancer.

Keywords: Effectiveness, Evaluate, Professional Students, Risk Factors, Self Instructional Module

*Corresponding Author: Ms. Dipa Khaling Rai Department of Medical Surgical Nursing, National Medical College Nursing Campus, Birgunj, Nepal; Email- dipakhaling7@gmail. com 


\section{INTRODUCTION}

Today, increasing emphasis is placed on health, health promotion, wellness and self-care. Health is seen as resulting from a lifestyle that is oriented towards wellness. The result has been the evolution of a wide range of health promotion strategies, including lifetime health monitoring programs, environmental health programs, risk reduction and nutrition, and health education. ${ }^{1}$

Cancer is a group of diseases, characterized by uncontrolled growth and spread of abnormal cells. Cancer cells are described as poorly constructed, loosely formed and without organization. An organ with cancerous tumor eventually ceases to function. If the spread is not controlled it can result in death. For the treatment of cancer patients, Hospitals, beds, sophisticated equipments, machinery, drugs and the health care facilities such as trained nurses, oncologists, long stay of hospitalization are required. In addition to this, the indirect costs such as loss due to pre mature deaths, loss due to hindrance of productivity, economic dependence, etc cannot be quantified. ${ }^{2}$

The gastrointestinal tract (GIT) consists of a hollow muscular tube starting from the oral cavity, where food enters the mouth, continuing through the pharynx, oesophagus, stomach and intestines to the rectum and anus, where food is expelled. Primary purpose of the gastrointestinal tract is to break food down into nutrients, which can be absorbed into the body to provide energy. In case of gastrointestinal disease or disorders, these functions of the gastrointestinal tract are not achieved successfully. ${ }^{3}$

Smoking is linked with an increased risk of stomach cancer. Stopping smoking or never smoking decreases the risk of stomach cancer. Also, chronic infection with Helicobacter pylori (H. pylori) bacteria is linked to an increased risk of stomach cancer. When $\mathrm{H}$. pylori bacteria infects the stomach, the stomach may become inflamed and cause changes in the cells that line the stomach. Over time, these cells become abnormal and may become cancer. ${ }^{4}$

Not eating enough fresh fruits and vegetables is linked to an increased risk of stomach cancer. Some studies show that, eating fruits and vegetables that are high in vitamin $\mathrm{C}$ and beta carotene may lower the risk of stomach cancer. Also shows that, whole-grain cereals, carotenoids, green tea, and substances found in garlic may lower the risk of stomach cancer. Eating a diet with a lot of salt may increase the risk of stomach cancer. ${ }^{5}$

It is widely held that, 80 to $90 \%$ of stomach cancers may be attributable to environmental and life style factors such as tobacco, alcohol and dietary habits. Primary cancer prevention refers to avoiding cancer causing substances in the environment or dietary elements associated with increased risk. It can be achieved by making life style changes that eliminate risky behavior before cancer occurs. For instance smoking cessation, dietary changes, reducing alcohol intake and exposure to chemical and ionizing radiation. Therefore, a critical element in fighting against stomach cancer is education of the professional students. Knowing the facts about stomach cancer will help them to reach the ultimate, that is, prevention of cancer. ${ }^{6}$

The preventive measures of gastric cancer includes cessation of smoking, and tobacco consumption, avoided salted, smoked, pickled and poorly preserved foods, eradication of H-Pylori etc. Diet rich in fibres, vegetables and fruits and antioxidant supplements (vitamins A, $\mathrm{C}$, and $\mathrm{E}$ and the mineral selenium) might reduce the chance of gastric cancer. Further research in this area is needed.

\section{MATERIALS AND METHODS}

The study was conducted among professional students of Aditya Group of Institutions in Bangalore. The investigator used Simple Random Sampling Technique for selecting 60 samples. The experimental approach was used with pre- experimental one group pre-test posttest design. In view of the nature of the problem and the accomplishment of the objectives of the study, a self-instructional module was prepared. A structured knowledge questionnaire was prepared to assess the knowledge of the samples. The questionnaire included 30 items. Content validity of the developed tool and SIM was established before the data collection. Reliability of the tool was ascertained by test-retest method using Karl Pearson's formula. The reliability of the tool was 0.89 . 


\section{RESULTS}

Data were analyzed using descriptive and inferential statistics. Analysis was done based on the objectives and hypotheses of the study.

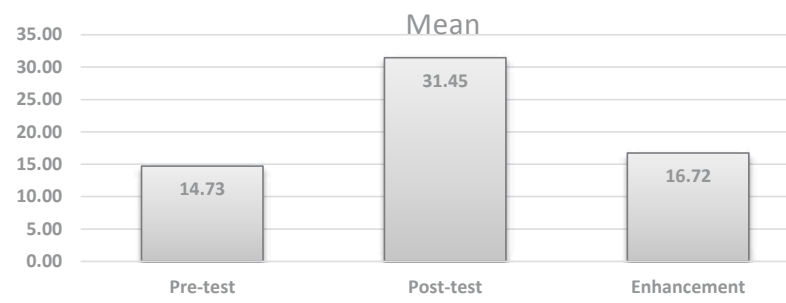

Figure 1 : Overall Mean Pre-Test and Post-Test Knowledge Scores of Professional Students

Table 1 : Aspect Wise Mean Pre-Test and Post-Test Knowledge Scores on Risk Factors and Prevention of Stomach Cancer among Professional Students

\begin{tabular}{|c|c|c|c|c|c|c|}
\hline \multirow{3}{*}{ SN: } & \multirow{3}{*}{$\begin{array}{l}\text { Aspect wise } \\
\text { knowledge }\end{array}$} & \multicolumn{4}{|c|}{ Knowledge of Respondents } & \multirow{3}{*}{$\begin{array}{l}\text { Paired } \\
\text { ' } t \text { ' test }\end{array}$} \\
\hline & & \multicolumn{2}{|c|}{ Pre-test } & \multicolumn{2}{|c|}{ Post-test } & \\
\hline & & Mean & SD & Mean & SD & \\
\hline I & $\begin{array}{l}\text { General } \\
\text { information of } \\
\text { stomach cancer }\end{array}$ & 2.16 & 1.84 & 4.06 & 0.94 & $7.53 * *$ \\
\hline II & $\begin{array}{l}\text { Risk factors of } \\
\text { stomach cancer }\end{array}$ & 5.17 & 1.83 & 11.64 & 2.36 & $6.19 * *$ \\
\hline III & $\begin{array}{l}\text { Types, symptoms, } \\
\text { diagnosis and } \\
\text { treatment of } \\
\text { stomach cancer }\end{array}$ & 3.47 & 1.53 & 7.18 & 0.82 & $6.71 * *$ \\
\hline IV & $\begin{array}{l}\text { Prevention of } \\
\text { stomach cancer }\end{array}$ & 3.93 & 1.07 & 8.57 & 1.43 & $9.35 * *$ \\
\hline & Overall & 14.73 & 6.27 & 31.45 & 5.55 & $22.68 * *$ \\
\hline
\end{tabular}

**Significant at $P<0.05$ level, df 59, table-value 2.6

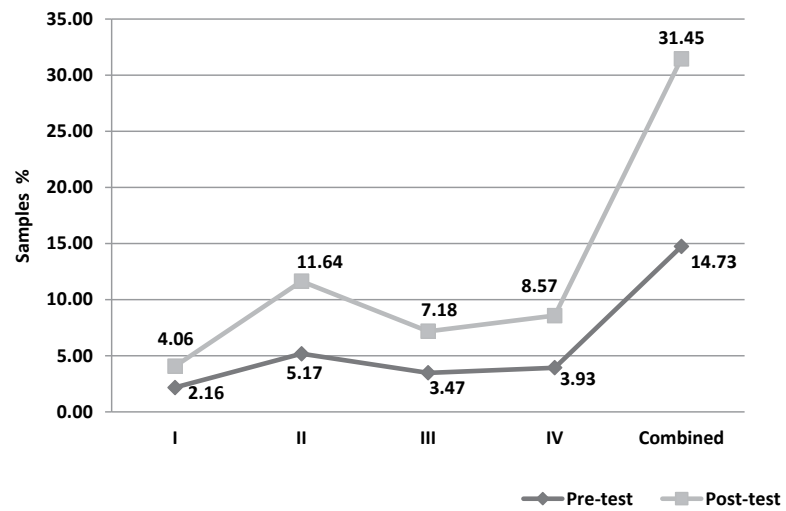

Figure 2 : Aspect Wise Mean Pre-Test and Post-Test Knowledge Scores on Risk Factors and Prevention of Stomach Cancer among Professional Students

\section{DISCUSSION}

The main aim of the study was to assess the effectiveness of the SIM on knowledge of risk factors and prevention of stomach cancer among professional students in selected colleges, Bangalore and samples gained significant knowledge after they were exposed to the self instructional module. The mean post-test knowledge score (31.45) was significantly higher than mean pre-test knowledge score (14.73). Thus, the SIM was found to be effective in enhancing knowledge of professional students regarding risk factors and prevention of stomach cancer.

There was significant association between mean pre-test levels of knowledge of professional students with their selected socio demographic variables analyzed by chi -square test. Such as area of residence, family history of stomach cancer and source of information regarding prevention of stomach cancer were higher values $(7.17,7.99$ and 35.28 respectively) when compared to the table value atP $\leq 0.05$ level of significance.

Above finding of the present study result showed that, $52 \%$ of girls had poor knowledge of stomach cancer with a mean score of $15.9 \pm 2.7$; majority $83 \%$ of boys had poor knowledge on stomach with mean score of $8.6 \pm 3.2$. There is also significant difference between knowledge of boys and girls regarding stomach cancer. Result also showed that, there was an association between demographic variables of age, education of parents and economic status and level of knowledge of boys and girls. Thus the study concluded that, there is a need for educational program to improve the knowledge of both boys and girls.

\section{CONCLUSION}

Cancer is one of the most important causes of morbidity and the magnitude of the problem is gigantic. Its burden, on the economy for providing health care will be substantial. Today, increasing emphasis is placed on health, health promotion, wellness, and self-care. Hence, cancer prevention and control is the most appropriate measure.

Eating fruits and vegetables that are high in vitamin $\mathrm{C}$ and beta carotene may lower the risk of 
stomach cancer. Eventually, whole-grain cereals, carotenoids, green tea, and substances found in garlic may lower the risk of stomach cancer. Also, eating a diet with a lot of salt may increase the risk of stomach cancer.

Primary stomach cancer prevention can be achieved by making life style changes that eliminate risky behavior before cancer occurs. For instance, smoking cessation, dietary changes, reduces alcohol intake, and exposure to chemical and ionizing radiation. Diet rich in fibres, vegetables and fruits and antioxidant supplements (vitamins A, C, and $\mathrm{E}$ and the mineral selenium) might reduce can decrease the chance of gastric cancer.

\section{ACKNOWLEDGEMENTS}

Nothing concrete can be achieved without an optimal inspiration during the course of work. There are several hands and hearts behind this work to bring it to this final shape for. Last but not the least, I extend my thanks to all those who have been directly or indirectly associated with study at various levels but not mentioned in this acknowledgement.

\section{REFERENCES}

1. Tanner M, Hollmen M, JunttilaTT. Amplification of HER-2 in gastric carcinoma: association with topoisomerase II alpha gene amplification, intestinal type, poor prognosis and sensitivity to trastuzumab. Ann Oncol. 16:273-8.

2. Black JM. Medical Surgical Nursing. $7^{\text {th }}$ ed. New Delhi: Elsevier publications; 2005. P. 747-8.

3. Smeltzer SC. Brunner and Suddarth's Text Book of Medical Surgical Nursing. $11^{\text {th }}$ ed. Lippincott-Raven Publishers; 2009. P. 1204-8.

4. Mergen H. Medical Check-Up Useful for Physician among New University Students during Enrolling Time to University. Gen Med. 2009; 6(2): 69-73.

5. Murthy NS, Aleyamma M. Cancer epidemiology, prevention and control. 2004.

6. Tomatis L, Huff J, Sandler, et al. Avoided and avoidable risks of Cancer carcinogenesis. 1997; 18(1): 97-105.

7. Anand P, Kunnumakar SA. Cancer is a preventable disease that requires major life style changes. Pharm Res. 2008; 25(9):2097-116. 